\title{
Crafting the imaginary: The deteriorating idea and sentimental plan of the ideal city
}

\author{
Erin Hinton and Craig Bremner
}

\begin{abstract}
The characteristics of the relationship between a city and its plan are not generally depicted as products of craft, nor are they discussed in terms of sentimentality. Despite the heroic modelling of the city based on illustrations of utopia, when looking at Walter Burley Griffin's claim for the Ideal city that became Canberra, there is evidence, however, that both craft and sentimentality might be important vectors shaping both the perception and projection of cities. This paper presents the case that the contradictory temporal vectors of the city and its plan (preservation versus projection) are paralleled in the notion of the sentimental (attachment to a past that will be misrepresented in the future). A similar temporal shift occurs in craft where mastery does not begin with ideas, rather it produces ideas. These shifts in time produce conditional cognitive and imaginary experiences of cities that differ from their planned conditions. The deteriorating image of the plan and its ideals produced by the dissonance between the actual and imaginary city, presents the possibility to apply the lens of sentimentality to its practices of representation. So, while the future city will no longer be depicted in reproductions of utopia, it will always be reproduced in plan as image and the city as imaginary, both in varying states of repair and (mis) representation. The signs of human activity (the crafting of micro-utopias), connections (cognitive maps), and experiences (the public imaginary), are experiences that craft the imaginary city in which, we speculate, it is possible to imagine people will want to live.
\end{abstract}

\section{Introduction}

The city of the future is no longer an ideal project (which shapes it as satire), but it can be a sentimental project (which shapes it by craft). The sentimental city captures the emotional and processual happenings, encounters, movements, and transitions of everyday life (the urban imaginary). Given the plan of the city is now a digitally reproduced object, and reproduction is the basis of accumulating skill, then the city of the future can neither originate from an idea nor generate ideas (hence the historic appeal of the ideal city). In this paper, however, we present a case that the future city might be crafted.

In this paper we speculate whether the practice of 'craft' might be used to give us a way to view and advance the urban project. If so, it opens the city to the lens of sentimentality as both a form of nostalgia (remembrance of things past, preservation, and the production of a view of the city future based on the past), and a method of production (conventional urban material in low volume production). Sentimentality, as a method of production, is a conscious process 
at the same time that it is a default product of the emotions - decisions are made about what to create with a view to the future, while keeping an eye on the reactive and the visceral. This sentimental duality (method + emotion) is then given a definition, logic and structure that permits outcomes to be evaluated in reference to the shaping of the city. From this notion of sentimentality, from the material and method, craft might be an urban practice and also a 'by-product' of everyday urban experiences.

We conclude by clarifying that, while the future city can no longer be depicted in faithful reproductions of utopia, it can be crafted revealing signs of human activity, connections, and experiences, and it is these experiences that craft the public imaginary of the city.

\section{Plan and city as synonym}

Before the city was planned it was lived in. And then, to imagine the city as the sum of lived experiences, the imaginary, it had to be mapped. Almost instantly the map and plan became interchangeable; to show the way became the way to show. So the plan and city have developed a certain synonymity. Clearly, they are not the same and, while the plan maps a city, the experience of the city does not require a plan, although it might require a map.

The notion of the sentimental city is derived from a temporal polarity; nostalgia for a past that cannot be retrieved substituting for a future that tries to preserve a past. This causes a problematic relationship between the plan and the city because the apparently opposing temporal vectors of the sentimental still need to be mastered. It is easy to see what happens over time in the city but not so easy to see what happens over time to the plan. The project of the plan to abstract a possible future for the city is evidence of its temporal persuasiveness over its spatial authority. But it is the temporal and not the spatial that determines the life of the plan - its constant revision is caused by the steadily deteriorating image of what was a representation of the real city at one point.

And when we talk about craft and the city we imagine the city as alternately traditional material (we know it well) and nonstop project (constant repair of its fabric and image) (Sennett 2008). The disparity in scale, however, between the city and practice of craft would normally preclude the two things being considered together, if it were not for the abstraction of the city through the plan. As an abstraction of the city, the material of the plan is constantly being reworked, revised, and repaired, in a manner similar to the material practice of craft as it endeavours to master its medium. Somewhat paradoxically, while craft supposes mastery at some point in the future, the plan proposes the future will validate its mastery of the city. To achieve this the plan is totally reliant on the image. 


\section{Plan as misrepresentation}

From historical agendas of flourishing agriculture, military defence and spiritual power, to modern ideals of movement, sanitation, and aesthetics, the history of city planning has presented itself as a rational paradigm defined by heroic ideals of power and social transformation, best captured in the numerous influential illustrated urban utopias. The utopian image of the city was long exalted as an embodiment of an ideal future plan (Solinís 2006). The inevitable loss of collective faith in the ideals of the modern movement, however, and consequent rise of a newly recognised pluralist society, brought with it criticism of the rigidity of the 'contractual' promises of the utopian city, as embodied in the modern plan. In addition to this criticism, then, came more damning evidence in the form of increasingly rich global data on cities, populations, ecologies, economics, and other flows illustrating the discovery of limits of both the utopian image and the project of the city: spatial and social; imaginary and contractual; telos (end) and topos (place) (Frye 1965: 323).

The design response to this evidence has been mixed, and a possible reason for this is captured in Thierry de Duve's essay 'When form has become attitude - and beyond' (1994), in which he outlines three stages of transformation in art (and design) education in the twentieth century. According to de Duve's outline, in the original academic educational model, talent resided in the few and required skill, whereas Bauhaus replaced talent with universal creativity that just required a medium for its expression. Hence, since Bauhaus, everyone can be an artist (Borer 1997), or now, a designer, as Donald Norman (amongst others) suggests (Norman 2004) and, by extension - a city planner - keeping in mind the Bauhaus educational model has been applied almost universally to the disciplines of art, architecture and design, including urbanism since it spawned from these disciplines. In the academic model, skill dealt with the mastery of a medium that would permit the skill to be continuous. In the 'modern' Bauhaus model, however, skill is replaced by invention, which has since been reduced to producing continuous novelty, epitomised in early modern critiques such as Cedric Price's Fun Palace (1961), Guy Debord's Society of the Spectacle (1967), and Ettore Sottsass's Planet as Festival (Di Castro 1976). Superseding the Modern was the Postmodern, in which 'critical attitude' replaced creativity, but rapidly degenerated into artistic 'pose', and simply required a 'signifying practice' to convey its form in a soup of referentiality and replication. Ultimately, as creativity was replaced by pose, art and design could simply be willed into existence. Now digitally derived flows ensure that everything is imitated. Even the scale of a city can be readily understood to be simply 'willed into existence' and, in its case, suspended in a cloud of digitised representation (Rodgers \& Bremner 2011).

Following de Duve's critique on the impact of the Bauhaus on art and design education, the Bauhaus also encoded a linear design formula where idea originated the development of the object-type which was then imitated to produce a better world, (or the telos of the plan) in which a single public interest 
was assumed, generated, and propagated. By the late 1960s, this was censured as reductionist and oversimplified, and denounced as lacking in 'the complexity of life' (Jencks in Calinescu 1987: 282). What emerged subsequently was a pluralist, desire-based production formula, in which the value of homogenous objectives (ideal conditions) and innovation was superseded by an overwhelming interest in the generation of heterogeneous projects (conditional ideals). This shift away from adherence to a collective interest acted to dislocate the encoded design method from any notion of idea, and instead generated a circular dialogic between the object-type and its imitation, from which the originating idea was absented then, eventually, not even necessary.

It is no surprise, then, that planning defaulted to imitation as the origin of design at a time when it has become apparent that the relationship between the project and the production of the city has been changed by digital technology. And this scenario is also driving change over the terrain of thought and action about urban design. Where once ideas drove change, urban change now appears to be split between two projects whose temporal dimensions govern the city future. One is the 'prosumer' busily sharing the world-as-found, and the other, and counter to their digital reconstruction of the here-and-now, is the revival of projections of what-might-become depicted in ideal future locations that are visible in the boom in digital imagery of fantasy cities. In order to now imagine the city it is necessary to navigate time, not space, and competing time frames at that addictive cataloguing of the past and seductive schemes of the future. Instead of projecting 'what-might-become' (the city future) the digital is generating the design of an 'other' world where, under the weight of digital flows, the project has become to archive 'what-was' trying to sustain the unsustainable sentiment of the city. Imitation also appears to be the means of contributing to (and taking guidance from) this project forming a reassuringly derivative loop. Coincidently, the derivative also happens to be the most influential 'product' of global capital. Functioning as a financial medium of insurance against change the derivative generates the capital flows on which cities depend for their continued existence in the era of the production of nothing.

Over time, each technological change has enhanced the propagation of the plan and served to further alienate the notion of idea from the Bauhaus design formula. By accepting the plan of the city as a readily reproduced object, and given that reproduction is the basis of accumulating skill, the future of the city became an artefact that could neither originate from an idea nor generate ideas - it regressed into an image of the image of the project. The plan became little more than a reflection (misrepresentation) of nostalgia for the past and sentimental visions of an ideal future. The process of coding and decoding (repairing) that was once perceived as real was now exposed as a filter that eliminated aspects of reality as quickly as it invented others. Ideal spatial conditions were equated with ideal social conditions and, rather than a map of the city as a projection, the image of the plan conditioned the project. Now devoid of the idea, what had 
originated as an image of the 'real world' (a concept in itself misguided by the assumption that propagated imagery as real or absolute) was rapidly reduced to an endless cycle of imitation.

\section{Plan as deteriorating image}

The proliferation of the digital project and its defining 'ease of re-productivity' additionally compounded the reduction of the plan to not only a set of simplistic concepts but moreover, a mere image. And digital reproductivity has serialised the plan into an image of inescapable distended perspectives in which the issue of urbanism and its civic project (projecting cities for citizens) appears to have been lost.

The positive attitude to technology formulated by Reyner Banham's revision of the modern project in 1960 invested in the machine the expectation, and then the capacity, to reproduce/edit/copy the image to any selected scale in any given quantity. It removed the image of the plan from the notion of context, and instead generated a montage of fractured imagery into which the public, and indeed the greater social condition, were required to adapt. Here the plan emerges as author representation (narration), as images of possible futures predicated on ideals of the city plan as transformative of social conditions and, in this way, it constitutes misrepresentations of the world driven by sentimental indulgences of our feelings about being together (Midgley 1979; Jefferson 1983).

In the case of the developing urban condition, the ubiquity of the digital initially acted to transform the 'idea' into an image of itself, reducing urban visions and ideals to a reflection of the digital's own essence, constraints, and design. In this way, the digital itself both determined and created the dimensions of the static environment and the resulting social condition. In another (perhaps more sinister way), the reproductive capabilities of the digital acted to transform the plan into a diluted representation or deteriorating image of itself, with each consecutive reproduction generating an increasingly extraneous derivative of the original (albeit transformed). In this sense, the deterioration of the image was not only occurring in the digital sphere, but also in the physical, with each reproduced artefact - plan and city - deteriorating from the moment its physical form became tangible (Antin 1966; Smith 2011: 7).

The increased reliance on the technology of the digital image, and the impact of the same technology on the production of the image, simultaneously brought about a change in the role of the plan. What was once a project that engaged visionary ideals and the pursuit of ideal vistas, now involved the constant repair of the deteriorating image, and deterioration on a digital 1:1 scale. 


\section{The sentimental plan}

To accept that the reality of the urban future acknowledges the plan as an image and a reproduction removed from reality and, in this, a misrepresentation, then the notion of 'sentiment', as deeply embedded in this misrepresentation, must also be acknowledged.

It is generally agreed that there is something unwholesome about sentimentality. Whilst the term began life as an admirable attribute, its currency rapidly deteriorated to signify a brand of culpable naivety (Jefferson 1983: 519). Mary Midgley notes that the most abhorrent offence in sentimentality is its 'dishonest distortion of reality' in order to fulfil the desires of an emotional indulgence (a projection upon the world of a type of unreality) (Midgley 1979: 385). In this way sentimentality can be paralleled with the distortion of reality and/or misrepresentations associated with the ideals of utopia (Bauman 2003); one misrepresents to critique the here and now (embodied in satire) while the other misrepresents to indulge our feelings.

The influence of the sentimental on the plan recast the linear causational program that once existed between plan and public, and initiated a temporal correlation between the author of the collective experience (the planner), and the author of the individual experience (the public). In the case of the planner, we see sentiment evolve as a type of nostalgia - as an attempt to imagine the city by preservation of images from previous eras while projecting possible futures. Here the public are asked to imagine the city 'as if' - as the projection of a set of images - in contrast to 'as it was', and this practice binds society even more tightly to an imaginary past being laid out in the continuous present. The urban context, and indeed the image of the plan, emerges as a concept driven by temporal rather than spatial dimensions.

From the point of view of the public, the notion of sentimentality takes the form of 'the generalised mental picture of the exterior physical world that is held by an individual' (Lynch 1960: 4). This image is the product of both immediate sensations and memories of past experiences, and is the result of personal transactions from the contextual environment of the city. In navigating the city the context suggests distinctions and connections (both experienced and to be experienced), and the public, driven by individual perceptions, desires, and purposes, link the image to their personal project. The resulting image is 'being tested against the filtered perceptual input in a constant interacting process' (Lynch 1960: 6) which both limits and emphasises what is seen. That is, how we see and experience the city is how the city trains us to see and experience it.

Rather than locate us in a continuous past, the sentimental view reinvigorates the analysis of representation (the cognitive map), but on a more complex level than the mapping of city form (Lynch 1960). What emerges is an interesting convergence between the representation of city space, and the 'representation of the citizen's Imaginary relationship to his or her Real conditions of existence'; a methodological enrichment in the cognitive mapping process that positions 
the situational representations of the individual subject within the more vast and properly unrepresentable (or misrepresented) totality which is the image of the city (Jameson 1991). The total image in this context emerges as the 'public imaginary' - a collection of images made in minds by the imagination (that are not the stuff of fantasy). To reside in minds as a collection, the images have been moderated by experiences or the results of observations and encounters with the city. The public imaginary contains visual indications of how it feels to live in the city and describes the mental space in our relationship with the city. The public imaginary is the sum of representations formed by the mental images of the city and the cognitive map transforms this mental picture from unrepresentable to representable. Therefore, the nature of our relationship to the image - i.e., how we see and reproduce it - forms the basis of how information is interpreted and action is guided; 'The images we make of the world change our perception of the world and thus change our sense of reality of it' (Merleau-Ponty 2010: 19). In this way, the image, be it individual or collective, sensitises itself, and any plan attempting to capture the public imaginary can only be a sentimental misrepresentation of the everyday experience of the city. The influence of the sentimental on the thoughts and actions of the public may, however, begin to inform what could be termed 'a new emotional economy'; a re-investment in expenditure on emotional episodes, with a view to how these may reshape the future: 'It suggests that one's emotional responses to the world are typically determined by how one sees the world. And how one sees the world - our beliefs and the desires they inform - is central to how one shapes the world' (Jefferson 1983: 526). Therefore, the case we are assembling in this paper contends that understanding the view of the city as plan (a cognitive map) is very different to the experience of the plan as city (the public imaginary), and this difference opens the city to the lens of sentimentality as both a form of nostalgia (remembrance of things past) and a means of production. Sentimentality, as a means of production, is a conscious process at the same time as it is a default product of the emotions - decisions are made about what to create with a view to the future, while keeping an eye on the reactive and the visceral. This sentimental duality (means + emotion) is then given a definition, logic, and structure that then permits the evaluation of outcomes in reference to the development (shaping) of the city. To accept that the reality of the urban future acknowledges the plan as a misrepresentation, and this misrepresentation acknowledges the inclusion of the sentimental, then the future city might benefit from engaging with the process of how it might be possible to employ the means of craft through the lens of sentimentality to (re) locate (and possibly generate) ideas from derivative and disintegrating images of the plan. 
craft + design enquiry

\title{
Canberra as sentimental city/deteriorated image/ misrepresentation
}

\begin{abstract}
I have planned a city that is not like any other in the world. I have planned it not in a way that I expected any government authorities in the world would accept. I have planned an ideal city - a city that meets my ideal of the city of the future.
\end{abstract}

Walter Burley Griffin on Canberra, 1912 (Birrell 1964: 189)

Canberra is a city accustomed to critique and debate. As a planned city conceived on utopian ideals, the impulses that informed the design of the national capital are, in reality, as unresolved as they are unloved. The foundation upon which the plan for the city was designed was premised on two ideological assumptions that we would now call sentimental misrepresentations, 'The first was that a vigorous Australian national identity existed ... and that it could be symbolised in the layout of a capital city. The second was that city planning could create a better and healthier society، (Taylor 2005).

The first assumption (misrepresentation) embodies a sensitivity to the landscape that was based not on the realities of lived experience or cultural condition, but on picturesque representations, which were, by nature, bound up in objectification and idiosyncratic interpretation (Rigby 2006). Although the Griffin's (Walter and Marion) city layout follows the contours of the topography, the notion of the 'bush' in the 'bush capital' is ultimately demoted in favour of a 'quasi-spiritualist geometrical arrangement of circles and triangles' (Smith 2008: 80). This seemingly sentimental dismissal creates a tension in which the relationship of the plan to the physical environment, and indeed the presumed embodiment of a national identity, is no more than symbolic (Duggan 1998).

The second, and perhaps more prominent ideal, that of the creation of urban environments to engender new forms of community life, seems equally as misguided in its contradictory notions. As Ruth Eaton notes: 'the spatial models that are projected are indissociable from the social arrangements to which they are believed to correspond. Their production is guided by a long-standing conviction that the physical form of a city can both reflect and condition the workings of a society and the behaviour of its citizens' (Eaton 2001: 11).

Inspired by Ebenezer Howard's Garden City movement, the Griffin's design for Canberra endeavoured to create spaces that would promote the development of harmonious communities (Smith 2008: 81). This type of 'architectonic utopianism', however, brings with it questions of 'whether architecture and design in itself can be expected to effect socio-political change' (Rigby 2006: 175) where the rigidity of the utopian plan promotes a conceptual authoritarianism at odds with the diversity of human activity that it is supposedly designed to engender (i.e., an ideal community stripped of its communitarian idealism) (Smith 2008). 
In creating a plan for the city driven by the ideological forces of 'utopia', the Griffin's, inspired by the new century's transcendentalism, inadvertently set the plan up to fail. Under the direction of unachievable ideologies, the plan immediately became a utopian diagram - a non-place (as may be suggested by the term itself - the ancient Greek topos = 'place', and the prefix $u=$ 'not'); a model that could, in theory, be placed anywhere, but was, in practice, nowhere (Duggan 1998).

It is important to understand that another dimension of the legacy of the Griffin's is not necessarily the shape of Canberra, but the plan as visual residue of the pervasive narrative utopia; in particular the legacy of the 'transcendental' writers of the second half of the nineteenth century in America - Walt Whitman, Ralph Waldo Emerson, and most importantly Henry David Thoreau. It's an interesting coincidence that Canberra transformed itself through the addition of freeways in the 1970s at the same time as America revived transcendental literature. Typified by Jack Kerouac's 1957 novel On the Road, the freeway led the depiction of a new self-reliance that was embodied in the motorcar.

Instead of an ideal city, Canberra is a city wholly preoccupied with its plan, as evidenced by the National Capital Authority's dutiful Griffin Legacy (2004). This tendency finds expression in the static monuments of urban planning and architecture that have come to define the city, each standing faithful to the ideals of a modernist utopia that created them (deteriorating image, misrepresentation, and sentiment), with little evidence of the aleatory compulsions that truly shape cities - the piecemeal planning, retrospective policy, and ad hoc adjustments that shape from within, despite the legacy. Existing in a state of temporal inertia is the real legacy for Canberra; a cultural repository driven to produce the future city through totalitarian adherence to an unvarying historical paradigm. What was a visionary project has become a city of the nation's past; a failed exemplar of the egalitarian ideals of the nation it is supposed to represent (Smith 2008); no more than an archive in an illegible and ever-deteriorating narrative/image of the city. Then what of the public? The proud and loyal find themselves existing in a living museum, a city that did not (and could not) deal with the way the projected life might engage with the plan and the surrounding landscape;

On the floor of a tranquil valley, almost encircled by the blue wall of the Australian Alps, across the brown and silver paddocks watered by the Molonglo, architects with compass and set square had laid down the design for a city. It was to be the perfect modern capital, rootless, blameless, minutely regulated, of a partyless unsectarian beauty ... it was a shame that human beings should live there at all. (Barnard \& Eldershaw 1947: 94)

\section{Crafting the imaginary}

What is now commonly called the Global City is currently the subject of a vast research exercise, resulting in the fact that we know more about its future than 
its present. What this research tells us is that the future Global City requires the re-imagination of its processes and all forms of production. It requires a shift from the idea of the City of Capital (how the city has been shaped) to the City of Lived Experience (how the city is imagined), using the Sentimental City (how the city is seen) to produce ideas. As we have explained, the Sentimental City captures the emotional and processual happenings, encounters, movements, and transitions of everyday life.

In this paper we are proposing that crafting the plan doesn't produce the city, crafting the deteriorating image that is the plan sustains the idea of the plan in the hope that it might reveal ideas for the city. And this is important. As we explain, the idea appears to be locked in a derivative loop, imitating its objective under the influence of digital reproductivity. By contrast the scale, repetition, and purposefulness of the process of craft includes the consistent interrogation of its results, and eventually generates ideas from the objects that it shapes - that is, the idea is derived from the process. In the manner of the authors of 'Non-plan', the repair of imperfect, incomplete, deteriorated imagery, and the application of the sentimental imaginary, requires talent and improvisation, resistance and ambiguity as instructive generators (Barker et al. 1969). So, unlike planning a city (derived from the ideal), crafting a city is a different process (an ideal production process from which to derive ideas) through which an understanding of materiality and technique is combined with the acknowledgement/generation of a new set of material values - social and cultural. In this way the gradual generation of a city and its plan are derived through a process of small improvements, movements, additions, alterations, insertions, repairs - tireless material derivation - something akin to the crafting of micro-utopias (Wood 2007). While it is impossible to resile from the utopian concept of the future city (as the already mentioned boom in digital fantasy cities attest), the known limits to the same future negate its plan (the macro-view) leaving only micro-actions that we equate to craft. As such, the crafting process does not require a plan, it requires skill. The idea of the city results from the nonstop repair of the image of the city, in much the same manner Archizoom and Superstudio cartooned in the late 1960s (Branzi 2006; Lang \& Menking 2003), and Rem Koolhaas satirised in Junk Space in 2002. The crafting of a city adapts it to its setting, and expresses climatic conditions and its program and material essence, producing its political and aesthetic dimensions. The crafting of a city progresses through a process of micro-utopias as tireless material derivation in search of the idea of the city (Wood 2007).

Craft conducts a dialogue between practice and thinking (thinking in action, as Richard Sennett calls it); this dialogue evolves into forming habits, and these habits establish a rhythm between problem-solving and problem finding (Sennett 2008). Craft also develops specific relationships between thought and making, idea and execution, action and matter, learning and performance, self-identity and work, pride and humility. As ritual, craft does not require a concept - it produces concepts that circulate in its own processes to produce things that require mastery before new ideas emerge. Therefore, the iterative 'circularity' 
of craft produces questions, never answers. Craft relies on collaboration with method and material. Instead of imposing a preconceived idea, craft demands listening to its material. To paraphrase the earlier quote from Merleau-Ponty 'The images we make of the world change our perception of the world and thus change our sense of reality of it' - instead of the image sensitising itself, in this case, the material sensitises itself.

In the manner of craft the method of the plan reacts to the medium of the plan, it questions its own representation, and the plan does this because both craft and sentimentality reveal that the image is unreliable and misrepresents the idea of the city. The idea, therefore, as driving concept, can no longer be imagined to be the initiator of progress, as in the modernist program, and, if it is not at the beginning of the project of change, it must be located somewhere else. The question now, is where?

By perceiving sentimentality as a notion that frames understandings of emotional and processual happenings and experiences, then what is intrinsically founded in reality is characteristically sentimental, informing a new way of seeing the accumulating images of the city. Here sentimentality and planning are perceived as forms of nostalgia (remembrance of things past), and images of a future (charged with preserving the past). From this notion of sentimentality, from the material and method, craft might actually be an urban practice and also a byproduct of everyday urban experience, producing ideas that the plan cannot discern.

\section{Conclusion}

We argue that the future city is no longer an ideal project; it is a sentimental project. The way the planner views and projects the city is through the lens of sentimentality as both a form of misrepresentation and a possible means of production. The resulting Sentimental City, then, becomes a digitally reproduced misrepresentation, so its future cannot originate from an idea (or an ideal), but the actions caused by the need to constantly service its digital image may perhaps be crafting ideas - and one of the tasks ahead is learning to locate these ideas.

To imagine the city as the sum of lived experiences - the imaginary - it has to be mapped, so the plan is synonymous with the city even though, in most cases, the city precedes the plan. Canberra is the exception that opens up this relationship to the speculation presented in this paper. But it is not easy to see the real relationship between the plan and the city because it is time, and not space, that determines the life of the plan. The changes to the spatial city proceed slowly, while revisions to the plan are constant and instantaneous. The constant revision, partly due to the steadily deteriorating image of the plan, turns the project of the plan into an abstract representation of continuous, anonymous, possible futures. If it were not for the demands produced by the abstraction of 
craft + design enquiry

the city in the plan then the disparity between the city as a practice of planning and the practice of craft would normally preclude their comparison. As an abstraction of the city the material of the plan is constantly being reworked, revised, and repaired, in a manner similar to the material practice of craft. And the constant repair of the fabric and image of the city is the non-stop project we equate to the practice of craft.

Presenting a way of viewing the city, and in particular Canberra, as a sentimental project has been argued in order to present the case that the city demands the reimagining of its processes of reproduction (as image). It requires a shift from ideal, as characterised by its plan, to process, as characterised by experience. We argue that the misrepresentation inherent in its reproduction (sentiment) and the ongoing need for repair (craft) can be used to generate alternative methods of enquiry and discourse through which the city can be reviewed and re-advanced as a civic project (projecting cities for citizens) as opposed to a project of capital. To achieve this, instead of designing the plan, the plan should be to shape the city, project by project, through a process akin to craft, and because the image of the city will be constantly reworked, if it is crafted then it just might generate ideas for its future plan.

As the paper explains, while the future city can no longer be depicted in reproductions of utopia, it will always be reproduced in plan, and it can be crafted involving a sense of 'the hand' and revealing intimate, meaningful, tactile, haptic, everyday experiences. This is the future role for the planner - to consider the plan as image and the city as imaginary, both in varying states of repair and (mis)representation. In order to do this, and not reduce the results to fantasy, the city needs to be elevated from the plan in the manner presented in this paper - the ideal needs recalibrating (what is and is not possible) and the idea needs relocating (from novelty to skilfulness). Movements across transitions, boundaries, thresholds, and their by-products (even debris) are signs of human activity (the crafting of micro-utopias), connections (cognitive maps), and experiences (the public imaginary), events the plan cannot illustrate, and it is these experiences that craft the imaginary city in which it becomes possible to imagine people will want to live.

Erin Hinton is Assistant Professor Architecture and Course Convener Interior Architecture at the University of Canberra. She is currently completing her PhD in urban design and analysis methodology at Charles Sturt University.

Craig Bremner is Professor of Design at Charles Sturt University. His research explores design ideas as representations of not knowing. Exhibitions he has curated have been shown in the United States, United Kingdom, Australia and Japan. 


\section{References}

Antin, D. 1966, 'Warhol: The silver tenement', Art News, Summer, http://popartmachine.com/masters/article/1120

Augé, M. 2005, 'An interview with Marc Augé : "Tourism could well be the last utopia",' viewed 17 July 2008, Atopia, http://www.atopia.tk

Banham, R. (1960) 1980, Theory and Design in the First Machine Age, Cambridge: MIT Press.

Barker, P., with Banham. R., Hall, P. \& Price, C. 1969, 'Non-Plan: An experiment in freedom', New Society, vol. 338.

Barnard, M. \& Eldershaw, F. 1947, Tomorrow and Tomorrow, Melbourne: Dial Press.

Bauman, Z. 2003, 'Utopia with no Topos', History of the Human Sciences, vol. 16, no. 1, pp. 11-25.

Birrell, J. 1964, Walter Burley Griffin, University of Queensland Press.

Borer, A. 1997, The Essential Joseph Beuys, Cambridge, MA: The MIT Press.

Branzi, A. 2006, NO-STOP CITY: ARCHIZOOM ASSOCIATI, éditions HYX, Orléans.

Calinescu, M. 1987, Five Faces of Modernity: Modernism, avant-garde, decadence, kitsch, postmodernism, Durham.

Debord, G. 1994, The Society of the Spectacle, (La Société du spectacle 1967), New York: Zone Books.

De Duve, T. 1994, 'When form has become attitude - and beyond', in Stephen Foster and Nicholas deVille (eds), The Artist and the Academy: Issues in fine art education and the wider cultural context, Southampton: John Hansard Gallery, pp. 19-31.

Design Museum, 'Cedric Price: Architect (1934-2003)', viewed 25 Sept. 2012, http://designmuseum.org/design/cedric-price

Di Castro, F. 1976, Sottsass's Scrap-book: disegni e note, Milano: Casabella.

Duggan, L. 1998, 'A sort of mythical thing: Canberra as an imaginary capital', Journal of Australian Studies, vol. 22, no. 57, pp. 83-92.

Eaton, R. 2001, Ideal Cities: Utopianism and the (un)built environment, London: Thames and Hudson.

Frye, N. 1965, 'Varieties of literary Utopias', Daedalus, vol. 94, no. 2, pp. 323-47. 
Jameson, F. 1991, Postmodernism, or the Cultural Logic of Late Capitalism, Verso, pp. 80-92.

Jefferson, M. 1983, 'What is wrong with sentimentality?', Mind, vol. 92, no. 368, Oct., pp. 519-29.

Koolhaas, R., Junkspace, October, vol. 100, Spring 2002, pp. 175-90.

Lang, P. \& Menking, W. 2003, Superstudio: Life without objects, Milan: Skira.

Lynch, K. 1960, The Image of the City, Massachusetts: MIT Press.

Midgley, M., 1979, 'Brutality and sentimentality', Philosophy, vol. 54, no. 209, July, pp. 385-89.

Merleau-Ponty, M. 2010, Institution and Passivity: Course notes from the Collège de France (1954-1955), Northwestern University Press.

National Capital Authority, 2004, The Griffin Legacy, Canberra, viewed 25 Sept. 2012, , http://www.nationalcapital.gov.au/index.php?option=com_content\& view $=$ article\&id $=374 \&$ ltemid $=267$

Norman, D. 2004, Emotional Design: Why we love (or hate) everyday things, Basic Civitas Books.

Rigby, K. 2006, '(Not) by design: Utopian moments in the creation of Canberra', Arena Journal, vol.

25-26, pp. 155-77.

Rodgers, P.A. \& Bremner, C. 2011, 'Alterplinarity - Alternative disciplinarity', Studies in Material Thinking, no. 6, http://www.materialthinking.org/

Sennett, R. 2008, The Craftsman, New Haven: Yale University Press.

Smith, R. 2008, 'The literary destruction of Canberra: Utopia, apocalypse and the national capital', Australian Literary Studies, vol. 24, no. 1, pp. 78-94.

Smith, T. 2011, 'One and three ideas: Conceptualism before, during, and after conceptual art', e-flux journal, vol. 29, November, pp. 1-17.

Solinís, G. 2006, 'Utopia, the origins and invention of Western urban design', Diogenes, vol. 53, pp. 79-87.

Taylor, K. 2005, 'Living with heritage: Canberra, city in the landscape. Can it remain a city not like any other?', Monuments and Sites in Their Setting: Conserving Cultural Heritage in Changing Townscapes and Landscapes. ICOMOS 15th General Assembly and Scientific Symposium, 17-21 Oct., Xi'an, China, http://www.intemational.icomos.org/xian2005/papers/3-47.pdf

Wood, J. 2007, Design for Micro-Utopias: Making the unthinkable possible, London: Gower. 